\title{
Examining the relationship between Dental Technology students' learning styles and their performance in entrance tests
}

SADJ March 2020, Vol. 75 No. 2 p 67 - p71

A Vahed ${ }^{1}$, F Ally ${ }^{2}$

\section{ABSTRACT}

\section{Introduction}

Selection tests provide early indications of prospective students' competencies, skills and knowledge.

Knowledge of students' learning styles and their correlation to entrance tests can contribute to the debate on student retention and attrition rates in higher education, which have been dominant research focus areas in the past decade.

\section{Aim and objectives}

To investigate the relationship between Dental Technology students' learning styles and their performance in entrance tests at the Durban University of Technology.

\section{Design}

A retrospective cohort study design within a quantitative framework was used.

\section{Methods}

The 2019 first year students completed the VARK® questionnaire, which was used to determine their learning styles. The VARK results were compared against the data obtained from entrance tests. Cross tabulations and Fisher's Exact tests $(p<0.05)$ were used to analyse the data.

\section{Results}

Despite there being no correlation between students performances in entrance tests and their preferred

Author affiliations:

1. Anisa Vahed: DTech, Senior Lecturer, Dental Sciences Department, Durban University of Technology, Durban, South Africa. ORCID Number: 0000-0002-0164-9114

2. Fazila Ally: $P h D$, Lecturer, Basic Medical Sciences, Durban University of Technology, Durban, South Africa. ORCID Number: 0000-0003-1777-9041

Corresponding author: Anisa Vahed

Department of Dental Sciences, Dental Technology Programme,

Durban University of Technology (DUT),

P.O. Box 1334, Durban, South Africa, 4001.

Email: anisav@dut.ac.za

Author contributions:

1. Anisa Vahed: Conception and design, data analysis and interpre tation, drafting and revising of paper. - 55\%

2. Fazila Ally: Data collection, data interpretation, drafting and revising of paper - $45 \%$ learning styles, the most dominant learning styles among Dental Technology first year students were unimodal (kinaesthetic) and quadrimodal (VARK).

\section{Conclusions}

This evidence-based data is critical in developing more appropriate student selection and placement tests for the Bachelor of Health Sciences in Dental Technology, and other similar programmes.

\section{Keywords}

VARK, learning styles, Dental Technology, selection tests.

\section{INTRODUCTION}

Dental Technology is characterised as a region ${ }^{1,2}$ as it hinges at the interface between disciplinary knowledge and the field of professional practice. The teaching, learning and assessment of Dental Technology should facilitate connecting the discipline-specific theory to laboratory based practice in order to design and fabricate intra-oral prostheses. ${ }^{3-7}$ Dental Technology students therefore require both knowledge and skills, and are generally selected for this profession possessing both attributes.

Awareness of students' learning styles and its correlation to entrance tests can therefore contribute to the debate on low student retention and increased attrition rates in higher education, which have been dominant research focus areas in the past decade. ${ }^{8-11}$

James, D'Amore and Thomas defined learning styles as the habitual manner of gaining knowledge, skills or attitudes through study and experience. ${ }^{12}$ Fleming and Mills' "Visual, Aural, Read/Write and Kinaesthetic" (VARK) model is a meta-strategy to understand undergraduate student learning preferences, particularly as a way of improving student retention rates. ${ }^{13}$

Visual learners prefer to see information and use visual aids. Aural learners, by contrast, prefer to listen and speak before reading and writing. Read/write and kinaesthetic learners tend to continually read and write the information and learn by doing and performing tasks respectively. ${ }^{14,15}$ 
Importantly, several other authors have argued that understanding the learning styles of students, especially when they enter higher education, can enable both lecturers and students to reach the desired outcomes of the curriculum. ${ }^{16-19}$

This is pertinent in Dental Technology as prospective first year students are required to complete a set of entrance test comprising of manual dexterity and the Standardised Assessment Test for Access and Placement (SATAP) tests.

Ultimately, knowledge of learning styles could be used to increase the self-awareness of students and lecturers whilst potentially alerting them to their weaknesses and strengths. ${ }^{17}$

Using a retrospective cohort study design within a quantitative framework, this study aimed to investigate the relationship between Dental Technology students' learning styles and their performance in entrance tests at the Durban University of Technology.

The evidence-based data will assist the Dental Sciences department to develop improved selection and placement tests for the Bachelor of Health Sciences in Dental Technology programme, which is to be implemented in 2021.

\section{OBJECTIVES OF THE STUDY}

- To ascertain the learning styles of first year Dental Technology students using the VARK questionnaire.

- To compare and evaluate the VARK results against student performances in the entrance test in order to improve the student selection process and academic teaching practices.

\section{METHODOLOGY}

\section{Study design and sampling}

A retrospective cohort design within a quantitative framework was used to examine the relationship between dental technology students' learning styles and their performances in entrance tests. Creswell defined a quantitative method as a process of collecting, analysing, interpreting and writing the results of a study. ${ }^{20}$

The study followed a positivist paradigm. A positivist approach enables one to present the discipline sufficiently and rigorously as scientific experts, providing the platform to make strong claims on reliability and objectivity. ${ }^{21}$

A purposeful sampling technique was used. The target population was the 2019 first year Dental Technology students $(n=47)$ from the first year Dental Technology extended curriculum $(n=29)$ and mainstream $(n=18)$ programmes at the Durban University of Technology (DUT). Vahed and Cruickshank clarified that there are two entry routes into the Dental Technology programme, that is, through the mainstream programme and through the extended curriculum programme (ECP). ${ }^{22}$
Consequently, the minimum time for completion of the National Diploma qualification is three years for mainstream students and four years for ECP, as their first year of study extends over two years.

In light of this, it must be noted that there were 10 ECP Level 1 students who had applied for the Dental Technology programme in 2018. The 19 ECP Level 2 students were the 2017 applicants and were part of the 2019 main-stream class.

\section{Ethical considerations}

Ethical clearance and permission to conduct the study was obtained from DUTs Institutional Research Ethics Committee (IREC153/16). Permission to conduct the questionnaires was obtained from the Academic Head of Dental Sciences. Informed consent was sought from the participants.

\section{Data collection and analyses}

The VARK@ (Version 7.8) questionnaire, which consists of 16 multiple choice questions, was administered to the students.

Each question has four options that correspond to the four sensory modality preferences (i.e. Visual, Aural, Read/Write and Kinaesthetic), which determines students' learning styles. As noted by several authors students can select one or more choices based on the sensory modalities they prefer when learning. ${ }^{15,19,23}$

This was clarified to the Dental Technology students during data collection, who were encouraged to choose the option(s) that best suited them. The VARK questionnaire scoring sheet was used to calculate the learning style scores.

The results from the VARK® questionnaire were compared against the data from the entrance test results, which were extracted from the academic records and programme files located in the Dental Sciences department. These records included:

- Students' manual dexterity scores for four sections, which are drawing, carving, stone block and plasticine. Each section tested students' visual, hand dexterity, listening and communication skills, as well as their ability to follow instructions.

- The SATAP results, which included the scores for Academic Literacy, Mathematics (Maths A and Maths B), Science, and an essay. A point that deserves to be mentioned is that two hour Academic Literacy paper aims to test the ability to use language in an academic context by testing reading, comprehension and writing.

The Maths A section focuses on the numeracy and abstract mathematics content. The Maths B section, by contrast, tests understanding and comprehension of Mathematics. The 1.5 hours Science test assesses the scientific literacies expected of students entering higher education. ${ }^{24}$ 
Descriptive statistics (frequency, percentage, mean) and inferential statistics (correlations and cross tabulations) were used to analyse the data (SPSS $尺$ Version 25.0). The statistical significance of the results was determined using Fisher's Exact test $(\mathrm{p}<0.05)$. Validity and reliability of the VARK questionnaire has been established in previous studies. ${ }^{19}$

\section{RESULTS}

The students' response rate in this study was $92.2 \%$, which is deemed highly acceptable. There was no significant difference $(p=0.303)$ in the frequencies of students' learning preferences.

From the 47 Dental Technology students (18 males and 29 females) who participated in this study, 17 (36.2\%) preferred a unimodal and 30 (63.8\%) multimodal learning style. Among the multimodal group of students, 11 (23.4\%) were bimodal, 8 (17\%) were trimodal and 11 (23.4\%) were quadrimodal learners.

Among the unimodal learners, 1 (2.1\%) student preferred the visual, 3 (6.4\%) preferred the aural, 1 (2.1\%) the read/write and 12 (25.5\%) preferred the kinaesthetic modes of information processing.

From the students who preferred the bimodal information style of processing, 1 (2.1\%) preferred the visual and $\mathrm{read} / \mathrm{write}(\mathrm{VR})$ style, 4 (8.5\%) preferred the visual and kinaesthetic (VK) style, 5 (10.6\%) preferred the aural and kinaesthetic (AK) style and 1 (2.1\%) preferred the aural and $\mathrm{read} /$ write (AR) style.

Of the students who preferred three modes (trimodal) of information processing, 3 (6.4\%) preferred the visual, aural and kinaesthetic (VAK) style, 1 (2.1\%) preferred the visual, read/write and kinaesthetic (VRK) style, 4 (8.5\%) preferred the aural, read/write and kinaesthetic (ARK) style. Eleven (23.4\%) students preferred the visual, aural, read/write and kinaesthetic (VARK) modes of information processing.

A significant difference $(p<0.001)$ was noted between the learning styles of first year Dental Technology students.

As presented in Figure 1, the most common VARK mode distribution among students was kinaesthetic (26\%), followed by visual, aural, read/write and kinaesthetic (VARK) (24\%) and then aural and kinaesthetic (AK) (11\%).

Of the 47 students surveyed, 24 (52.2\%) students attended the entrance test in 2017 which consisted of the SATAP (Academic Literacy, Science, Numeracy) and manual dexterity (Bite block and Plasticine) tests. In 2018, 22 (47.8\%) students attended the entrance test, which consisted of the SATAP (Academic literacy, Science, Math A, Math B, Essay) and manual dexterity (Drawing, Stone block and Carving) tests.

The significant difference $(p<0.001)$ in the Academic Literacy section was noted with 20 (43.5\%) students achieving above average scores between $60-69 \%$, followed by 17 (37.0\%) students who obtained scores between $50-59 \%$, and 1 (2.2\%) student achieving a score between $80-100 \%$. There was a significant difference $(p<0.001)$ for the Science section with 4 (8.7\%) students obtaining scores between 70-79\%, 26 (56.5\%) between 50-59\%, while 2 (4.3\%) obtained between 30-39\%. There was a significant difference $(p<0.030)$ in the Maths A section with $1(4.5 \%)$ student obtaining scores between $70-79 \%$ and 9 (40.9\%) between $40-49 \%$.

The scores in the SATAP sections were also significantly different $(p<0.001)$ with $1(2.2 \%)$ student scoring between $70-79 \%, 30$ (65.2\%) between $50-59 \%$ and 13 (28.3\%) students between $40-49 \%$. The plasticine section of the entrance test had a significant difference of $p<0.001$ where $7(29.2 \%)$ students obtained scores between $80-100 \%, 30$ (50\%) between $60-69 \%$ and 2 (8.3\%) between 40-49\%.

There was a significant difference $(p<0.001)$ for the stone block section with $5(22.7 \%)$ students obtaining scores between 80-100\%, 11 (50\%) between 50-59\% and 1 (4.5\%) between 30-39\%. Ultimately, and in considering the total scores achieved in the manual dexterity sections, $11(23.9 \%)$ students obtained the highest scores between 70-79\%, 16 (34.8\%) between 60-69\% and 4 (8.7\%) obtained scores between $40-49 \%$.

There was no significant difference however, in the manual dexterity sections $(p=0.052)$ and SATAP tests $(p=0148)$ against the students' modes of information processing. Notably however, 30 students obtained scores between 50-59\% with 8 (17.4\%) preferring kinaesthetic, 8 (17.4\%) visual, aural, read/write and kinaesthetic (VARK), 3 (6.5\%) aural and 3 (6.5\%) visual and kinaesthetic (VK) modes of information processing. From the 13 students who scored between $40-49 \%$, $4(8.7 \%)$ preferred kinaesthetic, $3(6.5 \%)$ aural, and kinaesthetic (AK) and 2 (4.3\%) aural, read/write and kinaesthetic (ARK) modes of information processing.

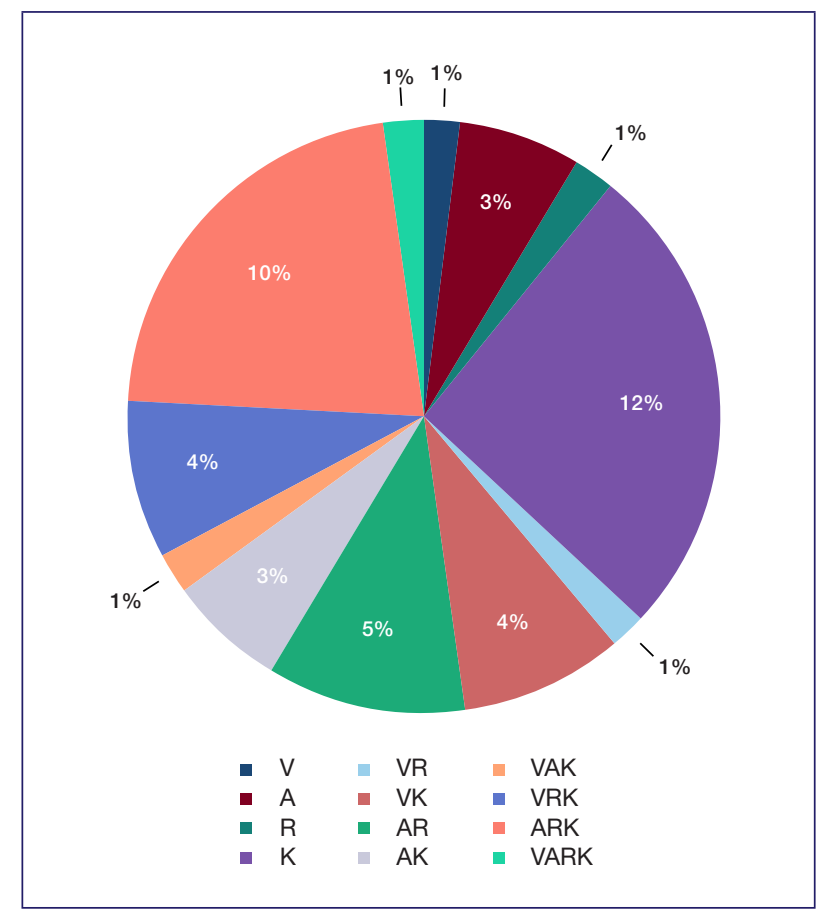

Figure 1. VARK mode distribution among first year Dental Technology students. 
The highest score obtained by 1 (12.2\%) student was between $70-79 \%$. This student preferred the read/write mode of information processing.

As illustrated in Table 1, cross tabulation results between the manual dexterity sections and VARK results revealed that out of the 16 students who scored between 60-69\%, 5 (10.9\%) preferred kinaesthetic and $5(10.9 \%)$ preferred aural, read/write and kinaesthetic (ARK) modes of information processing.

\begin{tabular}{|c|c|c|c|c|c|}
\hline $\begin{array}{l}\text { Learning } \\
\text { Style }\end{array}$ & $40-49$ & $50-59$ & $60-69$ & $70-79$ & TOTAL \\
\hline v & 0 & 0 & 0 & 1 & 1 \\
\hline A & 2 & 1 & 0 & 0 & 3 \\
\hline $\mathbf{R}$ & 0 & 1 & 0 & 0 & 1 \\
\hline K & 1 & 4 & 5 & 2 & 12 \\
\hline VR & 0 & 1 & 0 & 0 & 1 \\
\hline VK & 0 & 2 & 1 & 1 & 4 \\
\hline AR & 0 & 1 & 3 & 1 & 5 \\
\hline AK & 0 & 1 & 2 & 0 & 3 \\
\hline VAK & 0 & 0 & 0 & 1 & 1 \\
\hline VRK & 0 & 1 & 0 & 3 & 4 \\
\hline ARK & 1 & 2 & 5 & 2 & 10 \\
\hline VARK & 0 & 1 & 0 & 0 & 1 \\
\hline TOTAL & 4 & 15 & 16 & 11 & 46 \\
\hline
\end{tabular}

Among the 15 students who scored between 50-59\%, $4(8.7 \%)$ preferred kinaesthetic and 2 (4.3\%) visual and kinaesthetic (VK) modes of information processing. Students scoring between 40-49\%, 2 (4.3\%) preferred an aural, followed by 1 (2.2\%) kinaesthetic and 1 (2.2\%) aural, read/write and kinaesthetic (ARK) modes of information processing. From the students who scored between $70-79 \%$, 3 (6.5\%) preferred visual, read/write and kinaesthetic (VRK), 2 (4.3\%) kinaesthetic and 2 (4.3\%) aural, read/write and kinaesthetic (ARK) modes of information processing.

\section{DISCUSSION}

There was no significant difference $(p=0.303)$ in the frequencies of students' learning preferences, which suggests that there is no distinction between the different learning preferences among the first year Dental Technology students.

A factor contributing to this is the small number of students enrolled in the Dental Technology first year programme. Regardless of this, the results revealed that most Dental Technology students (68\%) had multimodal learning styles.

This result correlates with $\mathrm{Al}-\mathrm{Saud}^{17}$ and Marwaha, Bhagat and Kapoor $^{18}$, who revealed that the dominant learning preference among undergraduate dental students was multimodal.

The aforementioned predominant mode of information processing aligns with Dental Technology teaching, which mainly focuses on the 'know-how' knowledge of laboratory based practices.
The unimodal kinaesthetic learners, however, may not be stimulated during didactic theory lectures. Resonating with $\mathrm{Al}-\mathrm{Saud}^{17}$ and Cruickshank and Vahed ${ }^{7}$, active teaching and learning strategies therefore need to be considered and varied according to the level and subjects being taught while taking cognisance of the diversity of students.

Discipline-specific games, didactic lectures to group discussions, laboratory demonstrations, problem-based learning and project-based assignments are some exemplars of active learning strategies adopted by academic teachers. ${ }^{3-5,7}$ Ultimately, and in support of Al-Saud's argument, using a range of teaching methods can help students to learn effectively and enable them to adapt to any style a learning situation may require. ${ }^{17}$

Despite, there being no significant difference $(p=0.497)$ between the manual dexterity sections and VARK results, it can be gathered from Table 1 that a significant relationship exists between students' kinaesthetic (K) and aural, read/write and kinaesthetic (ARK) modes of information processing and their performance in the manual dexterity sections.

Consistent with several authors, having knowledge of students' modes of information processing enables academic teachers to structure and deliver lectures better by adopting more suitable pedagogies to accommodate their students' learning preferences. . $^{9,17}$ Importantly, this could improve students' retention rates, an area which dominates the South African higher education debate.8,10,11 Conversely, and in corroboration with other authors, students also need to be encouraged to develop more suitable learning strategies to achieve a higher level of academic performance. ${ }^{14,17}$ In fact, students may need to adapt to learning modalities that are different from their own preferences because of real-life laboratory constraints.

\section{Limitations}

Limitation of this small-scale study must be acknowledged. This study was limited to DUT and had a limited sample size. Hence, the results cannot be generalised to other South African Universities of Technology offering the training of dental technicians.

Another limitation of the study was that the results did not account for confounding factors such as demographics (age and gender), socio-economic and/or firstgeneration status and ethnic background. The aforementioned limitations therefore point to the future directions of a longitudinal study that seeks to track students from their first to their final year of study.

In particular, to investigate the relationship between students' performance in entrance tests with their overall academic performance and the association to learning styles. The longitudinal study will aim to provide an in-depth analysis of the requirements necessary to encourage constructive learning and students' success in the Bachelor of Health Sciences in Dental Technology, which is to be implemented in 2021. 


\section{CONCLUSION}

While there is no relationship between students' performances in entrance tests and their preferred learning styles, the most dominant learning styles among Dental Technology students shown in this study were unimodal (kinaesthetic) and quadrimodal (VARK).

The insights from this study provide the impetus for Dental Technology academics to use a diverse range of pedagogical practices to enable unimodal learners to adjust their learning styles such that they can connect the theory and laboratory-based practices.

Students accepted into the Bachelor of Health Sciences in Dental Technology programme should complete the VARK questionnaire at each level of study and prior to lectures commencing so that early interventions to assist them to succeed academically can be implemented and monitored throughout their student career.

\section{Acknowledgement}

The authors extend their gratitude to Ms Lindokuhle Nzima and Ms Tandzile Ginindza for their assistance with this research; the 2019 Dental Technology students at DUT who participated in this study and completed the VARK questionnaire.

Special thanks to the statistician, Mr Deepak Singh for his expert guidance in interpreting the results and enriching the research, overall. Dr Gillian Cruickshank thank you for making the time to expertly proof read this paper.

\section{References}

1. Bernstein B. Pedagogy, Symbolic Control and Identity: Theory, Research, Critique Revised ed. Maryland: Rowman \& Littlefield Publishers Inc. 2000.

2. Bernstein B. Class, Codes and Control: Theoretical Studies towards a Sociology of Language Revised ed. London and New York: Routledge, 2003.

3. Vahed A. The Tooth Morphology Board Game: An innovative strategy in tutoring Dental Technology learners in combating Rote Learning. In: Stanfield M, Connolly T, eds. $2^{\text {nd }}$ European Conference on Games Based Learning (ECGBL). Hotel Silken Diagonal, University of Catalunya, Barcelona, Spain: Academic Conference International, 2008.

4. Vahed A, Cruickshank G. Reflecting on Discoveries in Dental Technology. In: Doolittle PE, ed. $3^{\text {rd }}$ Annual Conference on Higher Education Pedagogy. Blacksburg Virginia, USA: Centre for Instructional Development and Educational Research (CIDER), 2011; 240: 3.

5. Vahed A, Khalili P. Muscle Mania" Multi Media Game: An exploration on the effectiveness of this learning intervention. 1st Southern African Conference on First Year Experiences. University of Stellenbosch, Western Cape, 2008.

6. Vahed A, Singh S. Facilitating epistemological access by developing students experiences of undergraduate research. In: València. UPd, ed. $3^{\text {rd }}$ International Conference on Higher Education Advances HEAd'17. Valencia: Editorial Universitat Politècnica de València, 2017; 224-30.

7. Cruickshank G, Vahed A. The collaborative exploration of teaching-and-learning strategies to reduce the 'at risk' identity of students: A case study in Dental Technology. $9^{\text {th }}$ ICED Conference 2012: Across the Globe Higher Education Learning and Teaching Proceedings. Bangkok, Thailand: Chulalongkorn University Printing House; 2012.
8. Council on Higher Education. A proposal for undergraduate curriculum reform in South Africa: The case for a flexible curriculum structure. Pretoria: CHE Press; 2013.

9. Feeley AM, Biggerstaff DL. Exam Success at Undergraduate and Graduate-Entry Medical Schools: Is Learning Style or Learning Approach More Important? A Critical Review Exploring Links Between Academic Success, Learning Styles, and Learning Approaches Among School-Leaver Entry ('Traditional') and Graduate-Entry ('Nontraditional') Medical Students. Teach Learn Med 2015; 27(3): 237-44.

10. Council on Higher Education. Higher Education Monitor: Access and throughput in South African Higher Education: Three case studies. Pretoria: CHE Press; 2010.

11. Council on Higher Education. VitalStats: Public Higher Education 2016. Pretoria: CHE; 2018.

12. James S, D'Amore A, Thomas T. Learning preferences of first year nursing and midwifery students: utilising VARK. Nurse Educ Today 2011; 31(4): 417-23.

13. Fleming ND, Mills C. Not Another Inventory, Rather a Catalyst for Reflection. To Improve the Academy: A Journal of Educational Development 199; 137-55.

14. Saran R, Kumar S, Pentapati K. Assessment of learning preferences among dental students using Visual, Aural, Read-Write, Kinesthetic questionnaire: An institutional experience. Journal of Dental Research and Review 2015; 2(1): 10-2.

15. Klement M. How do my Students Study? An Analysis of Students' of Educational Disciplines Favorite Learning Styles According to VARK Classification. Procedia Soc Behav Sci. 2014; 132: 384-90

16. Almigbal TH. Relationship between the learning style preferences of medical students and academic achievement. Saudi Med J. 2015; 36(3): 349-55.

17. Al-Saud LM. Learning style preferences of first-year dental students at King Saud University in Riyadh, Saudi Arabia: influence of gender and GPA. J Dent Educ. 2013; 77(10): 1371-8.

18. Marwaha K, Bhagat A, Kapoor N. Learning Style Preferences of Undergraduate Dental Students of a North Indian Dental College. Indian J physiology and pharmacology 2015; 59(2): 231-7.

19. Leite WL, Svinicki M, Shi Y. Attempted Validation of the Scores of the VARK: Learning Styles Inventory With Multitrait-Multimethod Confirmatory Factor Analysis Models. Educ Psychol Meas 2010; 70(2): 323-39.

20. Creswell JW. Research Design: Qualitative, Quantitative and Mixed Methods Approaches $2^{\text {nd }}$ ed. Thousand Oaks, CA: Sage.; 2014.

21. Hasan M. Positivism: to what extent does it aid our understanding of the contemporary social world? Qual Quant. 2016; 50(1): 317-25.

22. Vahed A, Cruickshank G. Integrating academic support to develop undergraduate research in Dental Technology: A case study in a South African University of Technology. IETI 2018; 55(5): 566-74.

23. Peyman H, Sadeghifar J, Khajavikhan J, Yasemi M, Rasool M, Yaghoubi YM, Nahal MMH, Karim H. Using VARK Approach for Assessing Preferred Learning Styles of First Year Medical Sciences Students: A Survey from Iran. J Clin Diagn Res. 2014; 8(8): GC01-GC4.

24. Use of the SATAP tests. Durban: Durban University of Technology. 